\title{
Microbiological Contamination of Bed Linen and Staff Uniforms in a Hospital
}

\author{
Anthony Pinon, Jessica Gachet, Virginie Alexandre, Sandra Decherf, Michèle Vialette \\ Unité de Sécurité Microbiologique, Institut Pasteur de Lille, Lille, France \\ Email: anthony.pinon@pasteur-lille.fr
}

Received September 4, 2013; revised October 20, 2013; accepted November 7, 2013

Copyright (C) 2013 Anthony Pinon et al. This is an open access article distributed under the Creative Commons Attribution License, which permits unrestricted use, distribution, and reproduction in any medium, provided the original work is properly cited.

\begin{abstract}
Hospital linen is clearly recognized as a potential reservoir for microorganisms and could be a vector of disease transmission. The aim of this study was to isolate, count and identify fungi and bacteria from different kinds of clean and dirty linen in a hospital. Microbiological samples have been collected on clean bed linen $(n=200)$, dirty bed linen $(n=$ $192)$ and staff uniforms $(n=192)$ by using contact plates. $55 \%$ of samples from clean bed linen were contaminated before contact with the patient, with a mean count of $3 \mathrm{cfu} / 25 \mathrm{~cm}^{2}$ (range: $1-117 \mathrm{cfu}$ ) when contaminated. Virtually all samples from dirty bed linen carried microorganisms, with a mean count of $23 \mathrm{cfu} / 25 \mathrm{~cm}^{2}$ (range $1-191 \mathrm{cfu}$ ). In addition, staff hospital uniforms showed the highest contamination rates in the study, with an average of $45 \mathrm{cfu} / 25 \mathrm{~cm}^{2}$ (range: $1-218 \mathrm{cfu}$ ). Microbial species were mostly bacteria commonly found in the environment or on human skin, such as staphylococci or micrococci. Nevertheless, $57 \%$ of the identified species may be opportunistic pathogens for humans, representing a risk for people with a deficient or weakened immune system, especially in cases of superinfection. Since contamination of linen seems to occur after washing, actively antimicrobial textiles would represent a valuable measure to prevent textiles from being a vehicle for transfer of microorganisms.
\end{abstract}

Keywords: Linen; Bed Sheets; White Coat; Contamination; Hospital Acquired Infections

\section{Introduction}

Healthcare-associated infections (HAIs) represent a heavy social and financial burden. In the USA, it was estimated that 1.7 million cases of HAIs occurred yearly, with almost 99,000 deaths related to these cases [1]. European figures give an average prevalence of $7.1 \%$, corresponding to 4.5 million nosocomial infections each year [2].

Direct contamination is not the sole way of acquiring HAIs; contamination through environment of the patient has been identified as a possible route. Indeed, items in contact with the patient or in its vicinity may be frequently contaminated. In two separate studies, $86 \%$ and $87 \%$ of stethoscopes were found to be contaminated with bacteria, including staphylococci $[3,4]$; potentially pathogenic bacteria were found on $81 \%$ of medical charts [5]. Textiles may act as reservoirs of microorganisms, since pathogens may be able to survive on such surfaces for periods ranging from a few minutes to several months $[6$, 7].

Various species of microorganisms, including some relevant for HAIs, have been isolated from hospital textiles.
A study on white coats [8] reported $95 \%$ contamination, while others found presence of Staphylococcus aureus in $23 \%$ of the white coats [9]; these bacteria appear to be found more specifically around sleeves and pockets [10]. Pathogens were also found on other medical staff uniforms [11], or on bed linen in patients' rooms [12]. Textiles may thus be responsible for transmission of pathogenic microorganisms to patients, as a few studies described transmission of microorganisms from uniforms to patient and bed linen [13], or from dirty bed linen to staff uniforms [14].

The aim of the present study was to evaluate the level of microbial contamination on hospital textiles, based on samples from clean and dirty bed linen, and from staff uniforms. The analysis was both quantitative and qualitative, including identification of microbial species.

\section{Materials and Methods}

\subsection{Interviews}

Methods for handling clean and dirty linen in the hospital have been recorded. The industrial launderer responsible 
for washing textiles was also interviewed.

\subsection{Sampling}

Two sampling campaigns were carried out in a French hospital on November and December 2011. Samples were collected exclusively by trained staff from the microbiology laboratory. Textiles were sampled according to the following plan:

- 20 non-occupied rooms were selected in various hospital departments. In each room, 10 samples were collected from the bed, which had recently been made by the staff: fitted sheet (two sampling points at the centre), draw sheet (two sampling points at the centre), upper sheet (inside and outside, at the centre), duvet (near the head), pillow (at the centre), pillowcase (centre and opening). 200 samples (referred to as "clean bed linen") were thus obtained.

- Bed sheets that had been removed after use were sampled in laundry rooms, which are actually storage rooms for dirty linen before packing and sending to the launderer. According to available pieces, fitted sheets, draw sheets, or upper sheets were sampled (respectively 25, 51, and 20 sheets), with two sample points at the centre per item, amounting to 192 samples (referred to as "dirty bed linen").

- Staff uniforms were sampled either in the room where dirty uniforms are returned before laundering, or directly on the person (for the second sampling campaign only). For each uniform, two sampling points were selected, one on the chest and one on the pocket (right by default, possibly left if the holder was present and indicated left-handedness). Job title and department of the staff member having worn the uniform were recorded. 96 uniforms were sampled, with two sampling points for each piece, making a total of 192 samples, regardless of the uniform's nature (white coat, scrub, or other).

Bed sheets were $50 \%$ polyester $/ 50 \%$ cotton, while uniforms were $65 \%$ polyester $/ 35 \%$ cotton.

\subsection{Microbiological Analysis}

The samples were taken by placing agar contact Hygicount 4N (AES Chemunex, Bruz, France) on each sampling point (during 15 seconds). The surface of the plates is $25 \mathrm{~cm}^{2}$. Plates were transported in ice to the laboratory. After incubation at $32.5+/-2.5^{\circ} \mathrm{C}$ for 48 to $72 \mathrm{~h}$, colonies were differentiated according to their macroscopic appearance: colour, opacity, bulging, gloss, and contour. The number of colonies of each type was counted. A copy of each colony type was then isolated on PCA (Plate Count Agar, AES Chemunex) for bacteria, or OGA (Oxytetracycline Glucose Agar, Biokar Diagnostics, Beauvais, France) for moulds. Bacteria isolated on PCA were iden- tified to the species level by API strips (bioMérieux, Craponne, France). Moulds were analyzed by scotch-test to determine their genus.

\subsection{Statistical Analysis}

Statistical computations and tests were done using R statistical software [15]. Statistical differences evaluated by Wilcoxon's test were considered as significant when $P$ value $<0.05$.

\section{Results}

\subsection{Laundry}

In the hospital, dirty bed sheets are collected by the staff in dedicated bags. These bags are stored in each aisle (corresponding to one half of a floor) before being gathered in a basement room where the launderer picks them up for washing.

Uniforms are labeled with an electronic chip: each staff member may collect up to 3 clean, personal uniforms per week. An automatic dispenser stores clean uniforms until claimed by the staff members. Dirty uniforms are returned when the person decides to, in a unique return point. They are then collected by the launderer for washing.

Washing is performed in industrial tunnel washers. Procedures include application of chemicals (bleach, antimicrobial products) and high temperatures (up to $80^{\circ} \mathrm{C}$ for washing, smoothing out by vapor). Clean items are packed in plastic bags. Periodic microbiological sampling of textiles leaving the laundry is performed.

In the hospital, clean bed sheets are stored in their plastic bags in a dedicated, clean room in each aisle. Beds are made by the hospital staff.

\subsection{Clean Bed Linen}

A summary of quantitative results on clean bed linen is presented in Table 1. Pillows, pillowcases, and duvets were the most frequently contaminated items. It was not possible to determine whether the department (floor/aisle) of the room had an influence on microbiological contamination, because of the incomplete and unbalanced repartition of sampled rooms.

According to species identified from samples, a summary showing most represented microbial genera is presented in Table 2. Almost one half of the samples contained Gram-positive cocci. Although most species correspond to common environmental or skin microflora, 53\% of bacterial isolates (present in 38\% of textile samples) may be opportunistic pathogens for immunocompromised patients. Examples of such identified species include various Staphylococcus species (91 isolates in 67 samples, 
Table 1. Contamination levels on clean bed linen, sorted by decreasing order of contamination frequency; Q1, Q3: lower and upper quartiles.

\begin{tabular}{|c|c|c|c|c|c|}
\hline \multirow{2}{*}{$\begin{array}{l}\text { Sampling } \\
\text { point }\end{array}$} & \multirow{2}{*}{$\begin{array}{l}\text { Contamination } \\
\text { frequency }\end{array}$} & \multicolumn{3}{|c|}{ Plate count, $\mathrm{cfu} / 25 \mathrm{~cm}^{2 \mathrm{~b}}$} & \multirow{2}{*}{ Signif. } \\
\hline & & Mean & Median [Q1, Q3] & Max & \\
\hline Pillow & $18 / 20$ & 5 & $6[3,9]$ & 30 & $\mathrm{AB}$ \\
\hline $\begin{array}{l}\text { Pillowcase } \\
\text { opening }\end{array}$ & $16 / 20$ & 3 & $3[2,6]$ & 14 & $\mathrm{ACD}$ \\
\hline $\begin{array}{l}\text { Pillowcase } \\
\text { centre }\end{array}$ & $15 / 20$ & 6 & $6[4,12]$ & 54 & B \\
\hline Duvet & $15 / 20$ & 5 & $4[2,10]$ & 117 & $\mathrm{BC}$ \\
\hline $\begin{array}{l}\text { Inside upper } \\
\text { sheet }\end{array}$ & $11 / 20$ & 3 & $2[1,6]$ & 24 & $\mathrm{BDE}$ \\
\hline Fitted sheet & $19 / 40$ & 2 & $1[1,3]$ & 12 & $\mathrm{E}$ \\
\hline $\begin{array}{c}\text { Outside } \\
\text { upper sheet }\end{array}$ & $6 / 20$ & 2 & $2[1,3]$ & 3 & $\mathrm{CE}$ \\
\hline Draw sheet & $9 / 40$ & 1 & $1[1,2]$ & 3 & $\mathrm{E}$ \\
\hline All & $109 / 200$ & 3 & $3[1,7]$ & 117 & \\
\hline
\end{tabular}

${ }^{a}$ number of samples with at least one cfu/total number of samples; ${ }^{b}$ for samples with non-empty plates; ' $r o w s$ that do not share an uppercase letter are statistically different $(\mathrm{P}$-value $<0.05)$.

Table 2. Microbial genera found on clean bed linen.

\begin{tabular}{cc}
\hline Genus & Number (\%) of samples \\
\hline Staphylococcus & $69(35 \%)$ \\
Micrococcus & $62(31 \%)$ \\
Bacillus & $14(7 \%)$ \\
Pseudomonas & $13(7 \%)$ \\
Aspergillus & $13(7 \%)$ \\
Other Gram-negative bacilli & $22(11 \%)$ \\
Other Gram-positive bacilli & $2(1 \%)$ \\
Other Gram-positive cocci & $4(2 \%)$ \\
Other moulds & $11(6 \%)$ \\
Not identified & $15(8 \%)$ \\
\hline
\end{tabular}

with two samples containing S. aureus), various Pseudomonas species (14 isolates in 13 samples), Bacillus cereus (two samples), Stenotrophomonas maltophilia (one sample), or Gardnerella vaginalis (one sample).

\subsection{Bed Sheets and Uniforms after Use}

Contamination of dirty bed linen and uniforms was significantly higher than that of clean bed linen (P-value < 0.05). Results on these items are summarized in Table 3. On average, contamination of uniforms was twice as high as contamination of dirty bed linen, although the latter were sometimes visibly soiled by organic fluids. When available, the time elapsed before the uniform was returned to the laundry (not necessarily connected to the time it was worn, since staff members may keep clean uniforms in their lockers) was recorded; no correlation between this time and the level of contamination was found (data not shown).

Microbial genera identified on these textiles are presented on Table 4, as a summary from identified species. Staphylococci and micrococci were again the most widely found genera. Opportunistic pathogens represented approximately $58 \%$ of bacterial isolates (found in $95 \%$ of the textile samples), with various Staphylococcus species (557 isolates in 356 samples, including six samples with

Table 3. Contamination levels on bed linen and uniforms after use, sorted by decreasing order of contamination frequency; Q1, Q3: lower and upper quartiles.

\begin{tabular}{cccccc}
\hline \multirow{2}{*}{ Sampling point $\begin{array}{c}\text { Contamination } \\
\text { frequency }^{\mathrm{a}}\end{array}$} & \multicolumn{4}{c}{ Plate count, cfu/25 cm $\mathrm{cm}^{\mathrm{2b}}$} & \multicolumn{2}{c}{ Mean } & Median [Q1, Q3] & Max & \\
\hline Uniform pocket & $96 / 96$ & 49 & $55[32,87]$ & 218 & $\mathrm{~A}$ \\
Uniform chest & $96 / 96$ & 42 & $39[27,82]$ & 153 & $\mathrm{~A}$ \\
Upper sheet & $40 / 40$ & 24 & $23[11,61]$ & 191 & $\mathrm{~B}$ \\
Draw sheet & $102 / 102$ & 23 & $35[10,69]$ & 152 & $\mathrm{~B}$ \\
Fitted sheet & $49 / 50$ & 22 & $22[13,31]$ & 132 & $\mathrm{~B}$ \\
All & $383 / 384$ & 32 & $37[18,73]$ & 218 & \\
\hline
\end{tabular}

${ }^{a}$ number of samples with at least one cfu/total number of samples; ${ }^{b}$ for samples with non-empty plates; ${ }^{c}$ rows that do not share an uppercase letter are statistically different (P-value $<0.05)$.

Table 4. Microbial genera found on bed linen and uniforms after use.

\begin{tabular}{cc}
\hline Genus & Number (\%) of samples \\
\hline Staphylococcus & $357(93 \%)$ \\
Micrococcus & $340(89 \%)$ \\
Pseudomonas & $90(23 \%)$ \\
Bacillus & $66(17 \%)$ \\
Kocuria & $22(6 \%)$ \\
Pasteurella & $20(5 \%)$ \\
Ralstonia & $20(5 \%)$ \\
Other gram-negative bacilli & $68(18 \%)$ \\
Other gram-positive bacilli & $35(9 \%)$ \\
Other gram-negative cocci & $11(3 \%)$ \\
Other gram-positive cocci & $11(3 \%)$ \\
Moulds or yeasts & $8(2 \%)$ \\
Not identified & $25(7 \%)$ \\
\hline
\end{tabular}


S. aureus), Pseudomonas species (99 isolates in 90 samples), Bacillus species (34 isolates in 33 samples), Burkholderia cepacia (eight samples), Stenotrophomonas maltophilia (two samples), Aerococcus urinae (two samples), or Gardnerella vaginalis (one sample).

\section{Discussion}

The contamination level of dirty bed linen and uniforms evidenced in the present study is not uncommon. In a study, the authors found a microbial load on white coats after use at an average level of $24 \mathrm{cfu} / 25 \mathrm{~cm}^{2}$ [16], which is similar to the average level of $45 \mathrm{cfu} / 25 \mathrm{~cm}^{2}$ on uniforms in the present study. Other researchers sampled pajamas and bed sheets after one-night use, and found contamination levels ranging from $10^{2}$ to more than $10^{5} \mathrm{cfu} / 10$ $\mathrm{cm}^{2}$, which were larger than the average value of 23 cfu $/ 25 \mathrm{~cm}^{2}$ on dirty bed linen in the present study, but it was using a different sampling method, namely swabbing [17]. While bed linen contamination obviously originates mostly from the patient, uniforms were most likely contaminated both by skin microflora of the wearer and by contact with contaminated surfaces during the work shift.

Contamination of clean bed linen may appear more unexpected. In a number of studies, bed sheets sampled before use did not appear to carry microbial loads $[17,18]$. Another one found that counts on clean white coats were, on average, lower than $2 \mathrm{cfu} / 25 \mathrm{~cm}^{2}$ [16]. Washing procedures seem efficient for a removal of microorganisms [19]. However, contamination may occur after washing, but before contact with the patient: $14 \%$ of clean clothes in staff dressing rooms were found to be contaminated by S. aureus, and $10 \%$ by Clostridium sp. [20]. In the present study, since textiles leaving the laundry appear to be free from contamination (according to the launderer), although they are not claimed to be sterile, most bacteria found on "clean" bed linen likely originated from contact between clean bed sheets and uniforms, while the bed was made by the hospital staff. Since all samples from uniforms were positive for presence of microorganisms, regardless of the job of the wearer, these uniforms represent the most likely source of contamination of bed linen. This is in agreement with studies showing a transfer of microor- ganisms between various textiles [14]. It should be noted that the relatively highly contaminated pillows and du- vets are not changed as frequently as other items.

Most species identified from the samples correspond to usual members of skin microflora or to bacteria from the environment. Gram-positive cocci were the most prevalent species. These findings are coherent with other reports $[8,21,22]$. A number of studies specifically focused on searching HAI-relevant pathogens [2], mostly $S$. aureus or enterococci $[9,11,23]$. In the present study, only eight samples contained $S$. aureus (two clean bed items, three dirty bed sheets, three uniforms), and a single dirty bed sheet was contaminated with a non-pathogenic Enterococcus strain. However, a majority of isolated species may act as opportunistic pathogens, given the fragility and possibly weakened immune system of patients staying in a hospital. Bacterial isolates were not tested for antimicrobial susceptibility, since our final objective is to reduce the microbial load overall.

Contamination of staff uniforms may be considered as the most relevant hazard identified from this study. Indeed, although rules on hand hygiene have received wide attention and nowadays are largely complied with, benefits from clean hands may be partially lost by the fact that contaminated uniforms are worn from one room to another. The ubiquity of staff in a hospital thus represents a likely route of infection spread possibly involving textiles. Therefore, the use of treated textiles having an antimicrobial activity may be beneficial for limiting HAIs $[24,25]$. As a follow-up to the present results, similar tests will be performed by using bed sheets and uniforms with an antimicrobial activity.

\section{Acknowledgements}

This work was supported by Région Nord-Pas-de-Calais and European regional development fund in the framework of CROSSTEXNET ERA-NET Project Transnational Call 2010 (Antibacterial flexible barrier to fight nosocomial diseases in hospital and for medical applicationsBACNOS) from the European commission. Partners of the project BACNOS are gratefully acknowledged: Devan Chemicals NV, Colortex bvba, Centexbel, and Subrenat.

\section{REFERENCES}

[1] R. M. Klevens, J. R. Edwards, C. L. Richards, et al., "Estimating Health Care-Associated Infections and Deaths in US Hospitals, 2002," Public Health Reports, Vol. 122, No. 2, 2007, pp. 160-166.

[2] European Center for Disease Prevention and Control, "Annual Epidemiological Report on Communicable Diseases in Europe 2008," Stockholm, 2008.

[3] I. Youngster, M. Berkovitch, E. Heyman, Z. Lazarovitch and M. Goldman, "The Stethoscope as a Vector of Infectious Diseases in the Pediatric Division" Acta Paediatrica, Vol. 97, No. 9, 2008, pp. 1253-1255. http://dx.doi.org/10.1111/j.1651-2227.2008.00906.x

[4] M. E. Zuliani Maluf, A. F. Maldonado, M. E. Bercial and S. A. Pedroso, "Stethoscope: A Friend or an Enemy?" Sao Paulo Medical Journal, Vol. 120, No. 1, 2002, pp. 13-15.

[5] S. O. Teng, W. S. Lee, T. Y. Ou, Y. C. Hsieh, W. C. Lee and Y. C. Lin, "Bacterial Contamination of Patients' Medical Charts in a Surgical Ward and the Intensive Care Unit: Impact on Nosocomial Infections," Journal of Microbiology, Immunology and Infection, Vol. 42, No. 1, 2009, pp. 86-91. 
[6] A. N. Neely and M. P. Maley, "Survival of Enterococci and Staphylococci on Hospital Fabrics and Plastic," Journal of Clinical Microbiology, Vol. 38, No. 2, 2000, pp. 724-726.

[7] A. N. Neely, "A Survey of Gram-Negative Bacteria Survival on Hospital Fabrics and Plastics," Journal of Burn Care \& Rehabilitation, Vol. 21, No. 6, 2000, pp. 523-527. http://dx.doi.org/10.1097/00004630-200021060-00009

[8] M. Srinivasan, A. Uma, A. Vinodhkumaradithyaa, S. Gomathi and P. Thirumalaikolundusubramanian, "The Medical Overcoat-Is It a Transmitting Agent for Bacterial Pathogens?" Japanese Journal of Infectious Diseases, Vol. 60, No. 2-3, 2007, pp. 121-122.

[9] A. M. Treakle, K. A. Thom, J. P. Furuno, S. M. Strauss, A. D. Harris and E. N. Perencevich, "Bacterial Contamination of Health Care Workers' White Coats," American Journal of Infection Control, Vol. 37, No. 2, 2009, pp. 101-105. http://dx.doi.org/10.1016/j.ajic.2008.03.009

[10] W. Loh, V. V. Ng and J. Holton, "Bacterial Flora on the White Coats of Medical Students," Journal of Hospital Infection, Vol. 45, No. 1, 2000, pp. 65-68. http://dx.doi.org/10.1053/jhin.1999.0702

[11] C. Perry, R. Marshall and E. Jones, "Bacterial Contamination of Uniforms," Journal of Hospital Infection, Vol. 48, No. 3, 2001, pp. 238-241. http://dx.doi.org/10.1053/jhin.2001.0962

[12] E. Yamaguchi, F. Valena, S. M. Smith, A. Simmons and R. H. Eng, "Colonization Pattern of Vancomycin-Resistant Enterococcus faecium," American Journal of Infection Control, Vol. 22, No. 4, 1994, pp. 202-206. http://dx.doi.org/10.1016/0196-6553(94)90068-X

[13] J. A. Wilson, H. P. Loveday, P. N. Hoffman and R. J. Pratt, "Uniform: An Evidence Review of the Microbiological Significance of Uniforms and Uniform Policy in the Prevention and Control of Healthcare-Associated Infections. Report to the Department of Health (England)," Journal of Hospital Infection, Vol. 66, No. 4, 2007, pp. 301-307. http://dx.doi.org/10.1016/j.jhin.2007.03.026

[14] J. M. Boyce, G. Potter-Bynoe, C. Chenevert and T. King, "Environmental Contamination Due to Methicillin-Resistant Staphylococcus aureus: Possible Infection Control Implications," Infection Control and Hospital Epidemiology, Vol. 18, No. 9, 1997, pp. 622-627. http://dx.doi.org/10.1086/647686

[15] R Development Core Team, "R: A Language and Environment for Statistical Computing," R Foundation for Statistical Computing, Vienna, 2010.

[16] D. Wong, K. Nye and P. Hollis, "Microbial Flora on Doc- tors' White Coats," British Medical Journal, Vol. 303, No. 6817, 1991, pp. 1602-1604.

http://dx.doi.org/10.1136/bmj.303.6817.1602

[17] S. Malnick, R. Bardenstein, M. Huszar, J. Gabbay and G. Borkow, "Pyjamas and Sheets as a Potential Source of Nosocomial Pathogens," Journal of Hospital Infection, Vol. 70, No. 1, 2008, pp. 89-92. http://dx.doi.org/10.1016/j.jhin.2008.05.021

[18] M. Burden, L. Cervantes, D. Weed, A. Keniston, C. S. Price and R. K. Albert, "Newly Cleaned Physician Uniforms and Infrequently Washed White Coats Have Similar Rates of Bacterial Contamination after an 8-Hour Workday: A Randomized Controlled Trial," Journal of Hospital Medicine, Vol. 6, No. 4, 2011, pp. 177-182. http://dx.doi.org/10.1002/jhm.864

[19] K. E. Orr, M. G. Holliday, A. L. Jones, I. Robson and J. D. Perry, "Survival of Enterococci during Hospital Laundry Processing," Journal of Hospital Infection, Vol. 50, No. 2, 2002, pp. 133-139. http://dx.doi.org/10.1053/jhin.2001.1137

[20] A. Hambraeus, S. Bengtsson and G. Laurell, "Bacterial Contamination in a Modern Operating Suite. 4. Bacterial Contamination of Clothes Worn in the Suite," Journal of Hygiene (London), Vol. 80, No. 2, 1978, pp. 175-181. http://dx.doi.org/10.1017/S0022172400053523

[21] R. R. Banville and E. McNeil, "Microbiology of Drycleaning," Applied Microbiology, Vol. 14, No. 1, 1966, pp. 17.

[22] E. A. Hooker, S. Allen, L. Gray and C. Kaufman, "A Randomized Trial to Evaluate a Launderable Bed Protection System for Hospital Beds," Antimicrobial Resistance and Infection Control, 2012. http://dx.doi.org/10.1186/2047-2994-1-27

[23] J. R. Babb, J. G. Davies and G. A. Ayliffe, "Contamination of Protective Clothing and Nurses' Uniforms in an Isolation Ward," Journal of Hospital Infection, Vol. 4, No. 2, 1983, pp. 149-157. http://dx.doi.org/10.1016/0195-6701(83)90044-0

[24] G. Borkow and J. Gabbay, "Biocidal Textiles Can Help Fight Nosocomial Infections," Medical Hypotheses, Vol. 70, No. 5, 2008, pp. 990-994. http://dx.doi.org/10.1016/j.mehy.2007.08.025

[25] G. M. L. Bearman, A. Rosato, K. Elam, et al., "A Crossover Trial of Antimicrobial Scrubs to Reduce MethicillinResistant Staphylococcus aureus Burden on Healthcare Worker Apparel," Infection Control and Hospital Epidemiology, Vol. 33, No. 3, 2012, pp. 268-275. http://dx.doi.org/10.1086/664045 